\title{
Investigating the role of circulating CXCR5- expressing CD8+ T-cells as a biomarker for bacterial infection in subjects with pneumonia
}

Yu Shen ${ }^{1,2+}$, Qiu-xia Qu ${ }^{1,2+}$, Meng-ni Jin ${ }^{3}$ and Cheng Chen ${ }^{1,3^{*}}$

\begin{abstract}
Background: Recently, lymphoid follicle-confined and circulating CD8+ T-cells expressing the C-X-C chemokine receptor type 5 (CXCR5) were described, which was involved in anti-virus immune response. However, the dynamics and role of circulating CXCR5-expressing CD8+ T-cells during bacterial infection is unknown. So, we asked whether CXCR5+ CD8+ T cells were also generated during bacterial infections in lower respiratory tract.

Methods: The clinical data of 65 pneumonia patients were analyzed. The patients were divided into groups as tuberculosis, bronchiectasis and community or hospital acquired pneumonia (CAP, HAP). The sputum/bronchial secretion or bronchoalveolar lavage fluid (BALF) samples were taken for microbiological examination. The procalcitonin (PCT) was used to evaluate disease severity of these groups and compared among patients. We characterized the number and phenotype (PD-1 and CD103) of CXCR5 + CD8+ T cells in the peripheral circulation by flow cytometry in all individuals and analyzed their association with the serum PCT level and disease severity.

Results: Patients were mainly infected with Escherichia coli, Acinetobacter baumannii, Klebsiella pneumonia (K.p), Pseudomonas aeruginosa, and Staphylococcus aureus. Of note is the finding that PCT was weakly correlated with severity of respiratory infections. Furthermore, it was revealed an increase of CXCR5-expressing CD8+ T cells in peripheral blood of un-controlled CAP and progressive HAP compared controlled CAP and HAP, respectively $(P<0.05)$. Strikingly, the circulating CXCR5-expressing CD8+ T-cells in K.p-infected group was higher than that nonK.p-infected group $(P<0.05)$. Meanwhile, the ratio of CXCR5 $+C D 8+/ C D 8$ was positively correlated with PCT level $(P<0.05)$. In clinic, the determination of CXCR5-expressing CD8+ T-cells showed better results compared to PCT and can be useful for the prediction of exacerbation of CAP or HAP. Phenotypically, CXCR5+ CD8 + T cell expressed comparable level of inhibitory molecules PD-1 and lower CD103 compared to their CXCR5- counterparts.

Conclusion: The circulating CXCR5-expressing CD8+ T-cell has diagnostic value for current pneumonia severity, and could act as a biomarker for identifying a bacteria-associated exacerbation. These cells may provide novel insight for the pathogenesis of pneumonia.
\end{abstract}

Keywords: CXCR5, CD8+ T cell, Bacterial infection, Pneumonia, PCT

\footnotetext{
* Correspondence: chencheng@suda.edu.cn

Yu Shen and Qiu-xia Qu contributed equally.

Yu Shen and Qiu-xia Qu are co-first authors.

${ }^{1}$ Clinical Immunology Laboratory, the First Affiliated Hospital of Soochow

University, 188 Shizi Street, Suzhou 215006, China

${ }^{3}$ Respiratory Department, the First Affiliated Hospital of Soochow University,

188 Shizi Street, Suzhou 215006, China

Full list of author information is available at the end of the article
}

(c) The Author(s). 2019 Open Access This article is distributed under the terms of the Creative Commons Attribution 4.0 International License (http://creativecommons.org/licenses/by/4.0/), which permits unrestricted use, distribution, and reproduction in any medium, provided you give appropriate credit to the original author(s) and the source, provide a link to the Creative Commons license, and indicate if changes were made. The Creative Commons Public Domain Dedication waiver (http://creativecommons.org/publicdomain/zero/1.0/) applies to the data made available in this article, unless otherwise stated. 


\section{Introduction}

The coordinated differentiation of distinct effector populations of $\mathrm{T}$ cells is required for the efficient elimination of infected or cancerous cells. C-X-C chemokine receptor type 5 (CXCR5) is usually not expressed on CD8+ T cells, but it is required for the migration of follicular cytotoxic T cells (TFC) into B cell follicles. A population of CD8+ T-cells within lymphoid follicles was described as follicular CD8+ T-cells, characterized by the expression of CXCR5 and low or null expression of the C-C chemokine receptor type 7 (CCR7) [1]. This follicle confined CD8+ T-cell population exhibits lytic and nonlytic mechanisms and has been associated with viral infections control and cancer [2-4]. Interestingly, although the main localization of follicular T-cells are the secondary lymphoid organs, CXCR5-expressing T-cells are also found in peripheral blood [5]. Although it is clear that CXCR5 + CD8 + $\mathrm{T}$ cells was involved in anti-viral immune response, surprisingly little is known about it during bacterial infections in lower respiratory tract.

In clinical work, subjects with pneumonia can be diagnosed early by identifying pathogenic bacteria, detecting auxiliary inflammatory cytokines and observing clinical symptoms. Common laboratory examinations include blood routine, procalcitonin (PCT) [6, 7], white blood cell count (WBC), high-sensitivity C-reactive protein (hs-CRP) and neutrophil percentage (NEU\%). Here, we characterized circulating CXCR5-expressing CD8+ T-cells in pneumonia individuals and analyzed their association with PCT level. A potential role of CXCR5+ CD8+ T-cells in the setting of exacerbation of CAP and HAP was suggested, especially K.p infection. In addition, the expression profile of PD-1 and CD103 by CXCR $5+$ CD8+ T-cells was associated with their immune phenotype.

\section{Patients and methods} Study participants

In this study, 65 subjects with respiratory infection were included. The diagnosis of community acquired pneumonia (CAP) and hospital acquired pneumonia (HAP) was established according to the American Thoracic Society/ European Respiratory Society (ATS/ERS) standards. From all 65 patients, 5 patients were classified as tuberculosis, 11 patients were classified as bronchiectasis, 23 and 26 patients were grouped in CAP and HAP respectively. Patients with chronic obstructive pulmonary disease (COPD), asthma, auto-immune disease and malignant disease were excluded from this investigation. We considered patients progressively according to the criteria: pneumonia with two or more complications, for example acute respiratory distress syndrome, heart failure, septic shock, and secondary infections, and no improvement of at least one of these complications after 3 days of active treatment $[8,9]$. The study was approved by the Ethics Committee of our Institute of the First Affiliated Hospital of Soochow University.

\section{Flow cytometry analysis}

$5 \mathrm{~mL}$ of venous blood was drawn in an anti-coagulant tube from each subject. The following mixtures of antibodies were used for cell phenotype: anti-CD45- fluorescein isothiocyanate (FITC), anti-CD45-phycoerythrin-cyanine 7 (PE-CY7), anti-CD8-allophycocyanin (APC), anti-CD103PE-CY7, anti-PD-1-FITC and anti-CXCR5-phycoerythrin (PE). For the detection of CD8+ cells, cells were incubated with anti-CD45 mAb and anti-CD8 $\mathrm{mAb}$ in the dark at room temperature for $30 \mathrm{~min}$. The percentages of CXCR5expressing CD8+ cells were estimated by comparing the proportions of labeled cells with respect to total number of CD8+ cells from the subjects studied. Cell surface antigen (PD-1, CD103) expression was assessed by plotting them versus the given CD8 + CXCR5+ cells. The samples were analyzed by a FACS Calibur flow cytometer.

\section{Laboratory testing}

The sputum $(n=45)$ or bronchoalveolar lavage fluid (BAL, $n=20$ ) samples were delivered for microbiological examination. All samples were inoculated on bacterial media. PCT was measured using B.R.A.H.M.S. PCT automated immunoassays. The analytical sensitivity of all assays was $<0.25 \mathrm{~g} / \mathrm{L}$. All techniques were based on a one-step immunoassay sandwich method.

\section{Statistical analysis}

Statistical analysis was performed with SPSS statistical software (Version 19.0; SPSS Inc., Chicago, IL, USA). Student's $\mathrm{t}$ test was used to compare the CXCR5 + CD8+/CD8+ T-cell ratio between studied groups. Two-sided Fisher exact test were applied to determine the strength of association between the categorical variables. Receiver operating characteristic (ROC) curves were calculated to select the cut-off level of ratio of CXCR5 + CD8+ T cells/CD8+ cells and PCT value indicating exacerbation of CAP and HAP. All tests were two sided with a $P$-value of less than 0.05 being considered statistically significant.

\section{Results}

\section{Subject characteristics}

A total of 65 eligible patients were enrolled. Baseline characteristics of the subjects were listed in Table 1 . The patients include 53 men and 10 women and the median age was 63 years (range, 36-95 years). A total of 49 community acquired pneumonia (CAP) and hospital acquired pneumonia (HAP) individuals, 12 and 14 patients were controlled CAP and HAP respectively, 11 CAP and 12 HAP patients had disease progress. 
Table 1 Subject characteristics

\begin{tabular}{|c|c|}
\hline Type of disease & $n=65$ \\
\hline Tuberculosis & 5 \\
\hline Age (y) & $19-63$ \\
\hline Male & 4 \\
\hline Female & 1 \\
\hline Bronchiectasis & 11 \\
\hline Age (y) & $44-85$ \\
\hline Male & 8 \\
\hline Female & 3 \\
\hline Non-K.p & $7 / 12$ \\
\hline K.P & $0 / 12$ \\
\hline Controlled CAP & 12 \\
\hline Age (y) & $16-95$ \\
\hline Male & 7 \\
\hline Female & 5 \\
\hline Non-K.p & $1 / 12$ \\
\hline K.P & $0 / 12$ \\
\hline Progressive CAP & 11 \\
\hline Age (y) & $51-90$ \\
\hline Male & 8 \\
\hline Female & 3 \\
\hline Non-K.p & $3 / 11$ \\
\hline K.P & $3 / 11$ \\
\hline Controlled HAP & 14 \\
\hline Age (y) & 20-90 \\
\hline Male & 10 \\
\hline Female & 4 \\
\hline Non-K.p & $12 / 14$ \\
\hline K.P & $1 / 14$ \\
\hline Progressive HAP & 12 \\
\hline Age (y) & $41-81$ \\
\hline Male & 10 \\
\hline Female & 2 \\
\hline Non-K.p & $4 / 12$ \\
\hline K.P & $7 / 12$ \\
\hline
\end{tabular}

Circulating $\mathrm{CXCR5}^{+} \mathrm{CD} 8+$ T-cells in acute, chronic and exacerbated bacterial infection

To do this, we selected patients with CAP (resulting in acute infection), bronchiectasis $(n=11)$ and chronic airway-open associated respiratory tract infection (resulting in chronic infection, $n=5$ ). By flow cytometry, we characterized the number of circulating CXCR5expressing CD8+ $\mathrm{T}$ cells in all individuals (Fig. 1). Strikingly, we did not visualize a substantial accumulation of circulating $\mathrm{CXCR} 5^{+} \mathrm{CD}^{+} \mathrm{T}$ cells in chronically infected cases compared to chronically infected cases $(3.58 \% \pm 0.54$ vs $4.88 \% \pm 0.73, P=0.19$, Fig. 2a). Furthermore, CXCR5 + CD8+ T cells were not detected in peripheral blood in Mycobacterium tuberculosis infected patients $(1.19 \% \pm 0.38, n=5)$. Notable, as showed in Fig. $2 b$, during an exacerbation of CAP and HAP, there was a significant increase in circulating $\mathrm{CXCR} 5{ }^{+} \mathrm{CD}^{+} \mathrm{T}$ cells compared to disease-controlled CAP $(7.27 \% \pm 0.91$ vs $2.69 \% \pm 0.64, P<0.05)$ and HAP $(7.77 \% \pm 1.23$ vs $2.30 \% \pm$ $0.28, P<0.05)$, respectively. Of note was the finding that PCT was weakly correlated with severity of respiratory infections (Fig. 2c).

Pathogenic bacteria and circulating $\mathrm{CXCR}^{+} \mathrm{CD} 8+\mathrm{T}$-cells A total of 38 pathogenic bacteria were detected in 65 patients, of which 27 patients were infected with Gram negative bacteria, 5 patients were infected with Gram positive bacteria, 6 patients were infected with fungal. Patients in Gram negative group were mainly infected with Klebsiella pneumonia (K.p, $n=11$ ), Pseudomonas aeruginosa $(n=6)$, Acinetobacter baumannii $(n=4)$, while patients in Gram positive group were mainly infected with Staphylococcus aureus $(\mathrm{n}=4)$. We further calculated the ratio of CXCR $5+\mathrm{CD} 8+\mathrm{T}$ cells/CD8+ cells to decide if these cells were relatively increased or decreased in special pathogenic bacteria-infected patients. Interestingly, we found that the circulating CXCR5 ${ }^{+} \mathrm{CD} 8+$ T-cells were significantly elevated in K.p-infected subjects compared to non-K.p-infected subjects $(8.48 \% \pm 1.47$ vs $3.41 \% \pm 0.48, P<0.05$, Fig. $2 \mathrm{~d}$ ).

\section{Circulating $\mathrm{CXCR} 5^{+} \mathrm{CD}^{+}$T-cells are associated with evaluated PCT level}

PCT is an acute-phase protein released into the bloodstream mainly in response to bacterial infection. To explore the association of circulating CXCR5-expressing T-cells with the severity of bacterial infection, we determined the correlation between CXCR5 + CD $8+$ T-cells and serum PCT concentration. As shown in Fig. 3, frequencies of circulating $\mathrm{CXCR}^{+} \mathrm{CD} 8+\mathrm{T}$-cells were higher in patients with PCT $>0.5 \mathrm{ng} / \mathrm{ml}$ than these in patients with $\mathrm{PCT}<0.5 \mathrm{ng} / \mathrm{ml}(7.38 \% \pm 0.87$ vs $3.18 \% \pm 0.36, P<0.05)$. Correlations between PCT and CXCR5 + CD8 + T-cells were also identified $\left(\mathrm{r}^{2}=0.11, P=0.01\right)$. Accordingly, a positive correlation was found between the frequencies of CXCR5 + CD8+ T cells with PCT level in these individuals.

\section{Circulating $\mathrm{CXCR5} 5^{+} \mathrm{CD}^{+}$T-cells and diagnosis exacerbation of CAP and HAP}

We next examine whether the circulating $\mathrm{CXCR} 5^{+} \mathrm{CD} 8^{+}$ T-cells and PCT is associated with the occurrence of exacerbation of CAP and HAP. As showed in Fig. 4, the area under the PCT curve was $0.855(P<0.05,95 \% \mathrm{CI}$ : $0.733-0.977$ ) with sensitivity and specificity of 42.9 and $96 \%$, respectively, when the critical value was $1.75 \mathrm{ng} / \mathrm{ml}$. 


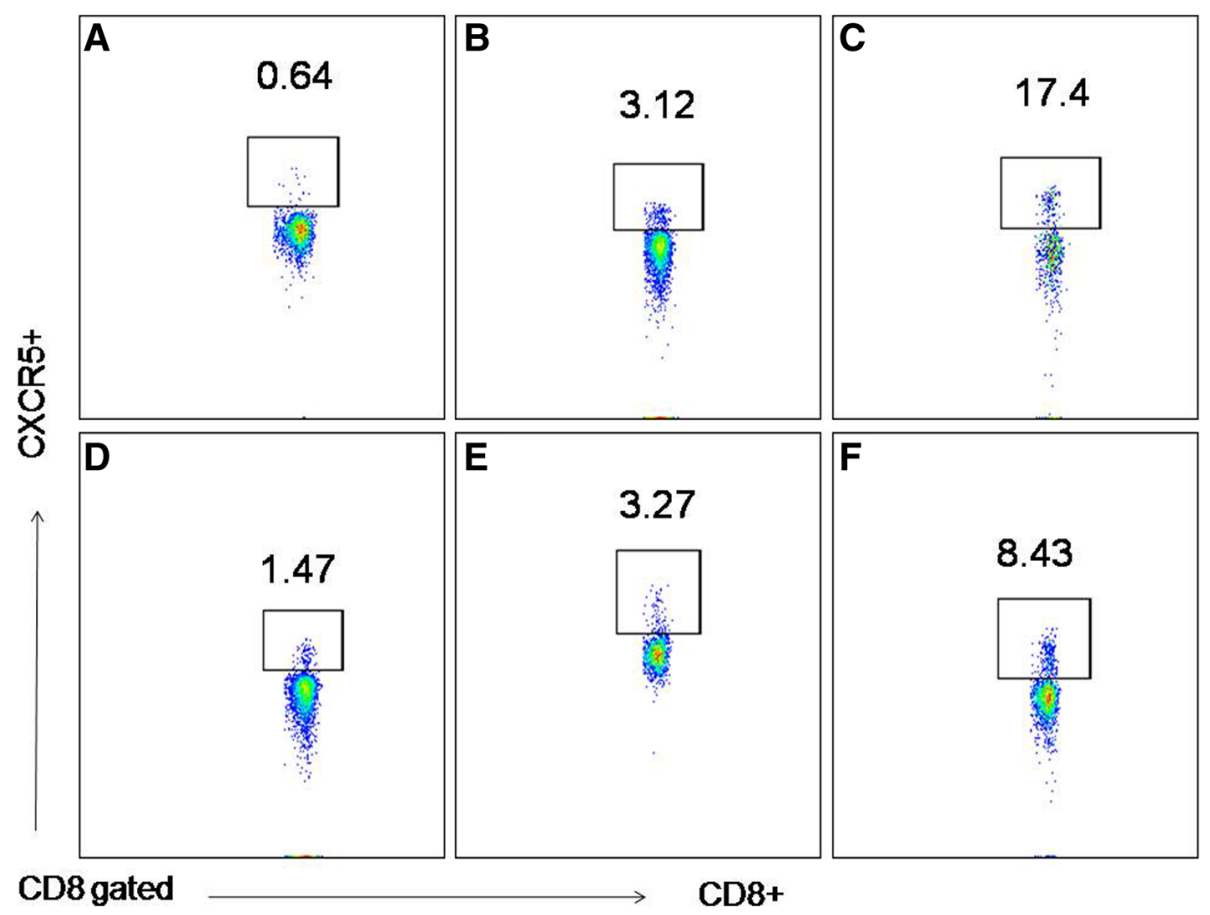

Fig. 1 The ratio of circulating CXCR5-expressing CD8+ T cells among CD8 + T cells in all individuals was determined by flow cytometry. a: tuberculosis, b: controlled HAP, c: un-controlled HAP, d: bronchiectasis, e: controlled CAP, f: progressive CAP. Representative FACS plots of CXCR5 expression in CD8+ T cells from lymphocytes are shown

The area under the ratio of CXCR5 + CD8+ T cells/CD8+ cells curve was $0.944(P<0.05$, 95\% CI: $0.875-1.000)$ with sensitivity and specificity of 90.5 and $93 \%$, respectively, when the critical value was $3.85 \%$. Furthermore, the combination of PCT and ratio of CXCR5 + CD $8+\mathrm{T}$ cells/CD8 + cells indicating exacerbation of disease was also analyzed. The sensitivity was found to be $90.5 \%$, specificity was found to be $84.6 \%$, and the area under the ROC curves was 0.952 (95\% CI: 0.896-1.000). It was suggested that the determination of CXCR5-expressing CD8+ T-cells alone can show good results for the clinical prediction of exacerbation of CAP or HAP.

\section{Expression of surface markers by CXCR5 + CD8+ T cells} Finally, we compared the phenotype of CXCR5+ and CXCR5-CD8+ T cells. Circulating CXCR5-expressing CD8+ T-cells exhibited low or null expression of the CD103 and had a comparable level of PD-1 compared to their CXCR5- counterparts (Fig. 5). Furthermore, in all pneumonia individuals, no detectable of CD103 + CD8 + $\mathrm{T}$ cells were seen in peripheral blood (data not show).

\section{Discussion}

Compared to T follicular helper cells (TFH) cells, current research on the CXCR5 + CD8+ T cells is relatively scarce. Several studies suggest that CXCR5+ CD8+ T cells represent a subset of follicular cytotoxic $\mathrm{CD} 8+\mathrm{T}$ cells and may contribute to virus control in B cell follicles [2, 3]. Some CXCR5-CD8+ T cells with the ability to contain lymphocytic choriomeningitis virus (LCMV) have been found in germinal center (GC) in mice and in blood of HIV-infected patients, where their levels correlated with viral load. In patients with HIV, the number of virus-specific CXCR5 + CD8+ T cell subset is inversely correlated with viral load in LNs [5]. Peripheral and GC CXCR5-CD8+ T cells are also present in SIV-infected macaques, where their levels increase after immunization, and it is higher in macaques controlling infection than ones who do not. CD8+ T cells can still contain viral replication in chronic infections although the mechanism of this containment is largely unknown $[10,11]$.

In this study, we aimed to determine if CXCR5 + CD8+ T cell was a valuable biomarker for bacterial infection in subjects with pneumonia. As expected, CXCR5+ CD8+ T cells are present in human peripheral blood and therefore can be readily quantified. As reported previously, the novel population of CXCR5 + cell was only generated in the chronically infected mice, showing that antigen persistence drives the generation of this novel CD8+ T cell subset $[2,3]$. Strikingly, we did not visualize a substantial accumulation of circulating $\mathrm{CXCR} 5^{+} \mathrm{CD} 8^{+} \mathrm{T}$ cells in chronically infected cases. However, patients on progressive CAP and HAP had higher frequencies of CXCR5 + CD8 + T cell compared with controlled CAP and HAP, respectively. These results suggest a 

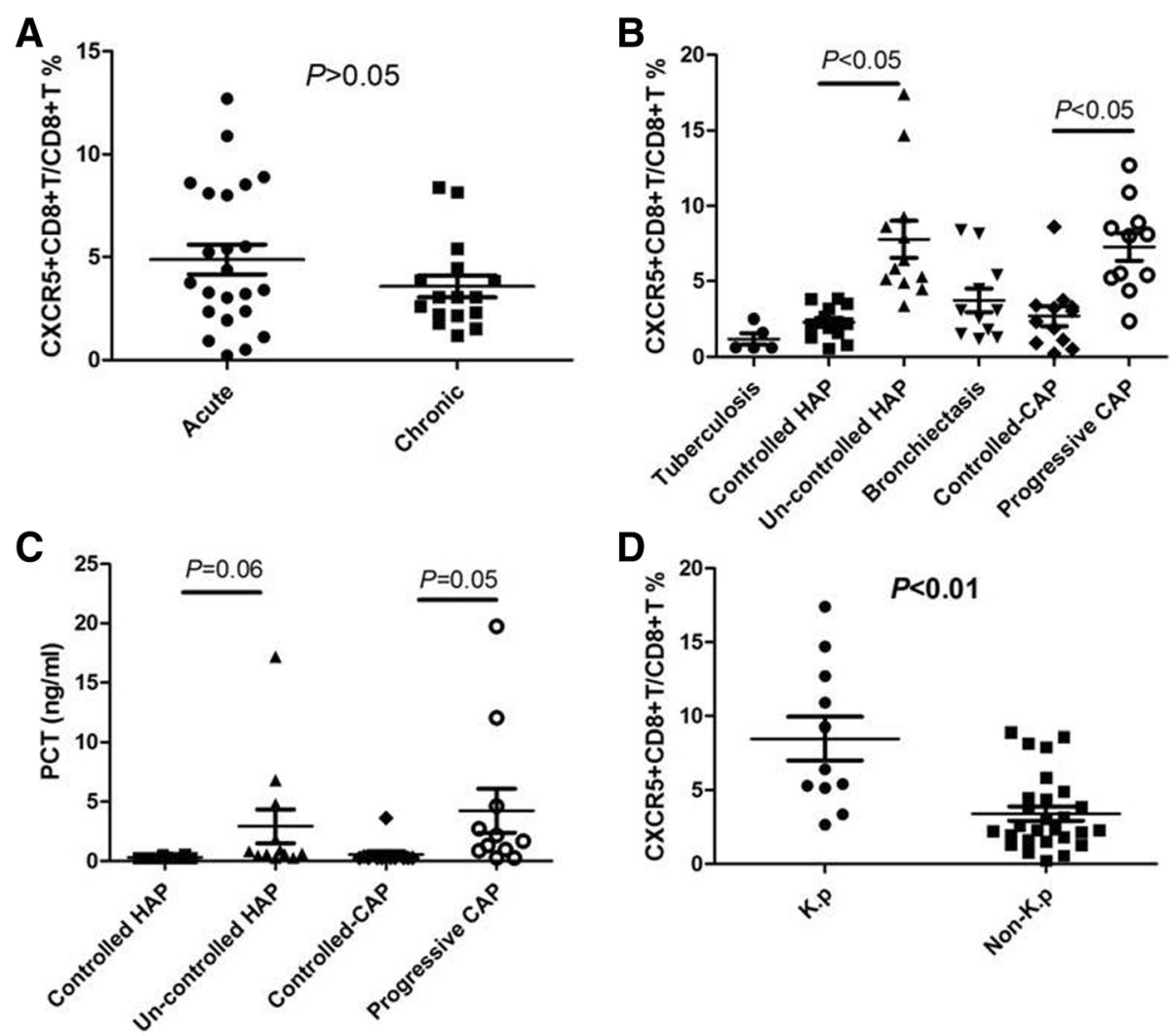

Fig. 2 CXCR5 $+C D 8+T$ cells are increased in the peripheral circulation in patients with uncontrolled CAP and progressive HAP compared controlled patient cohorts. Comparison of the circulating CXCR5 + CD8 + T cells and PCT between acute and chronic infection (a), among tuberculosis, bronchiectasis and community or hospital acquired pneumonia (b), between K.p and non-K.p infection (c, d). Results are presented as the mean with SD. Levels were compared by Student's t-test
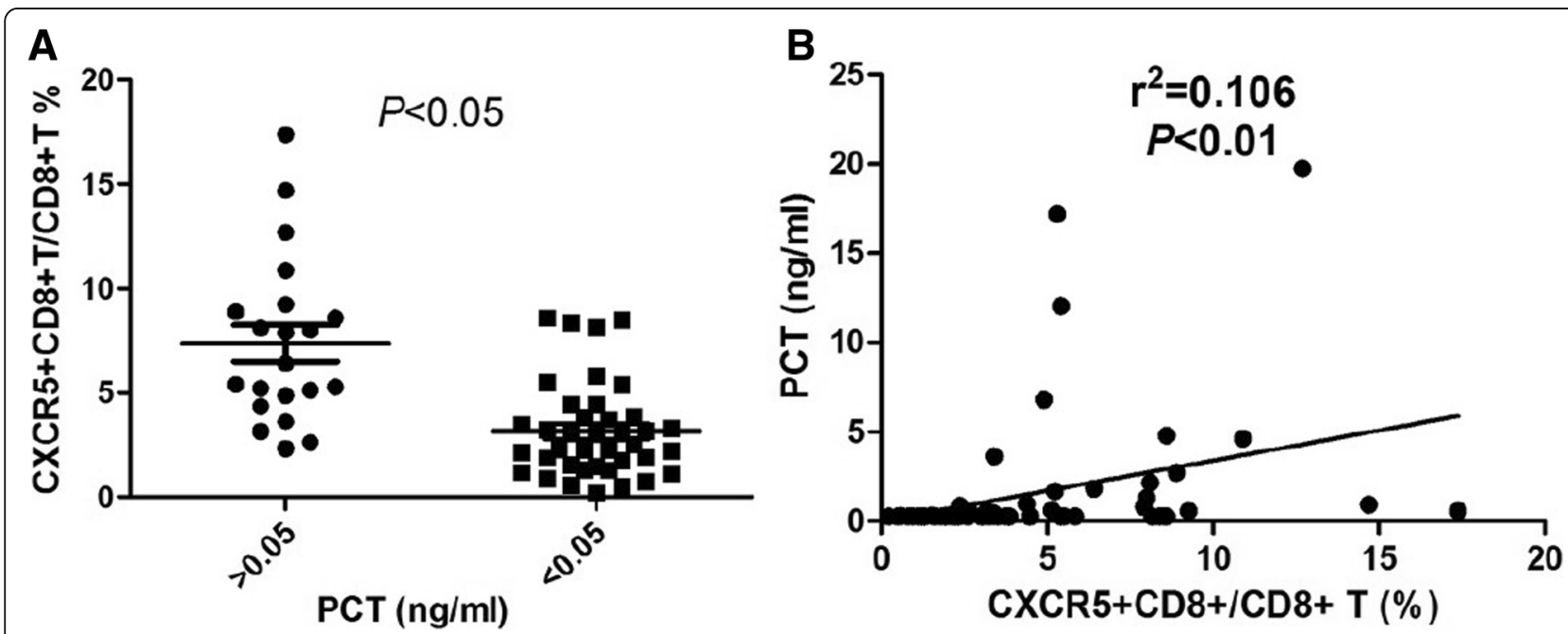

Fig. 3 Elevation of PCT was positively correlated with increased CXCR5 + CD8 $+T$ cells. $\mathbf{a}$, Levels of circulating CXCR5 + CD8 $+T$ cells between patients with PCT $>0.05$ and PCT $<0.05 \mathrm{ng} / \mathrm{ml}$. b. Scatterplot of CXCR5 + CD8+ T cell vs PCT. Each point in the scatter plot represents the value of two variables for a given observation. The rank Spearman correlation coefficient confirms that ratio of CXCR5 + CD8+ T cells and PCT are correlated 


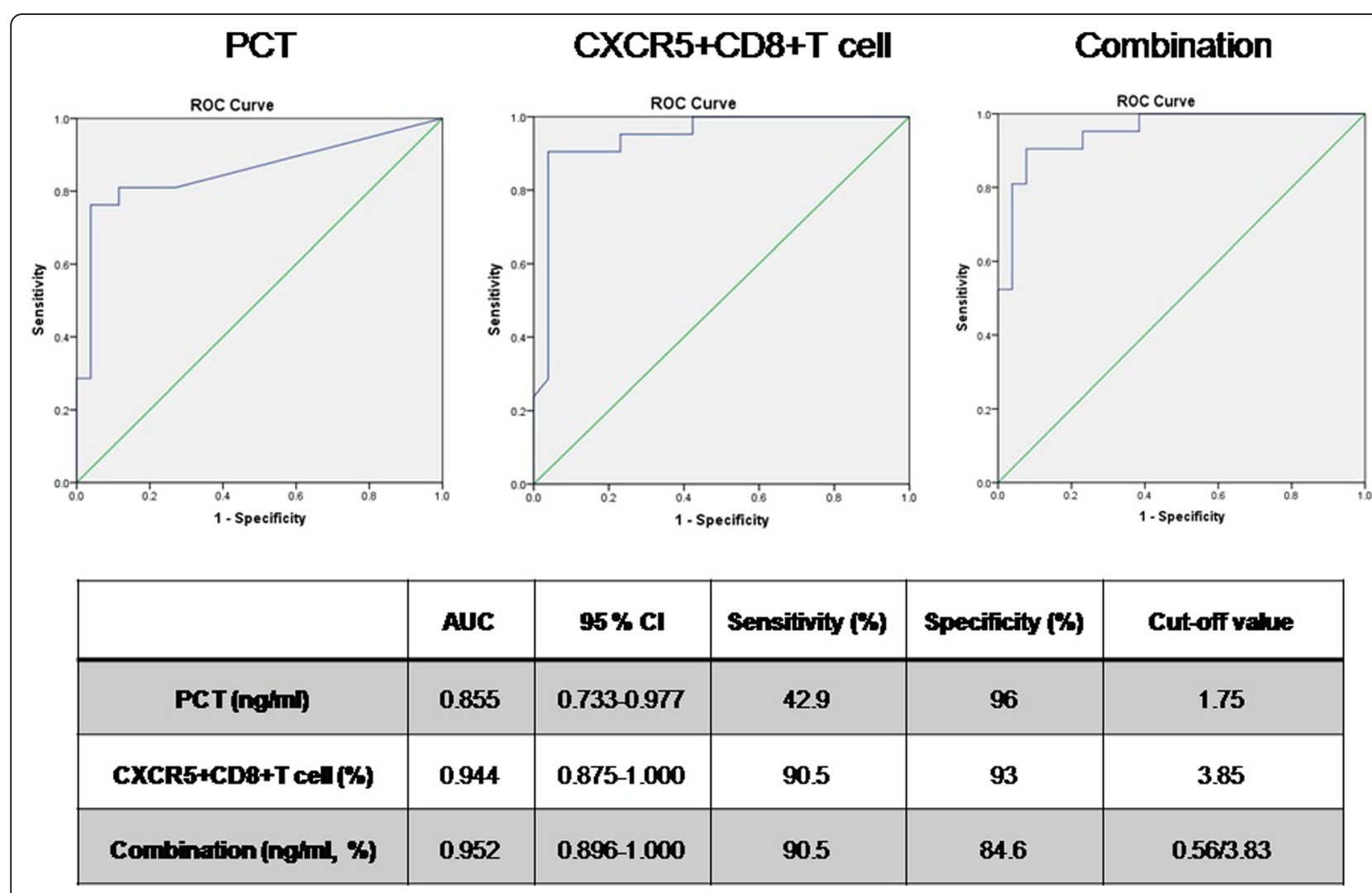

Fig. 4 CXCR5 $+C D 8+T$ cells could have diagnostic value when assessing the severity of bacterial respiratory infections. The optimal PCT, ratio of CXCR5 + CD8 + T cell and combination indicating exacerbation of CAP and HAP was analyzed

redistribution of this subset occur after the bacterial exacerbation. One possibility is that the bacterial antigens within lung tissues result in the increasing frequency of CXCR5+ CD8 + T cell in blood.

PCT is a kind of protein mainly produced by thyroid C-cells, which stays at a low level under normal body conditions. Several studies have suggested that PCT is the most useful biomarker for diagnosis of sepsis, with precedence over other laboratory indicators $[12,13]$. In this study, from analysis of ROC curves, CXCR5 + CD8+ $\mathrm{T}$ cells can alone act as a stronger predictive index of bacterial exacerbation when the PCT possess lower sensitivity to clinical prediction of exacerbation of CAP or HAP. With the advantages of simple and effective detection, it is
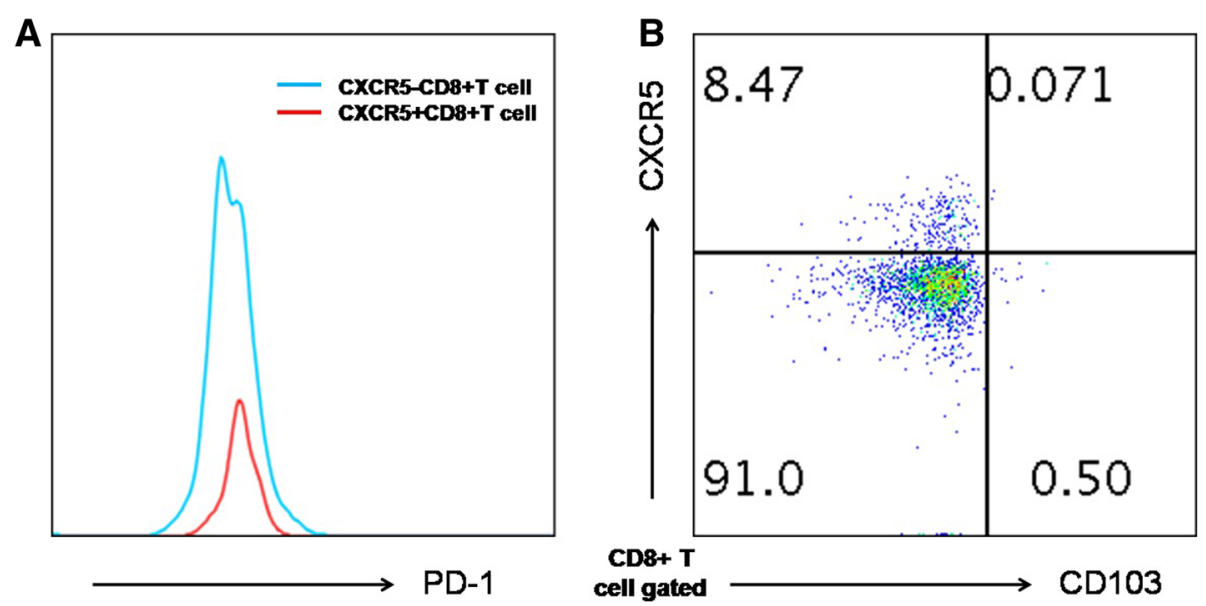

Fig. 5 The phenotype of CXCR5+ and CXCR5-CD8+ T cells. Circulating CXCR5-expressing CD8+ T-cells had a comparable level of PD-1 compared to their CXCR5- counterparts (a), exhibited low or null expression of the CD103 (b). Representative FACS plots are shown 
of great significance for avoiding missed diagnosis in patients with bacterial exacerbation and providing guidance for appropriate control.

Lung infections caused by carbapenem-non-susceptible Klebsiella pneumoniae constitute a worldwide problem associated with high rates of treatment failure and mortality $[14,15]$. In our collection of isolates, Klebsiella pneumonia infected-rate mounted to $16.9 \%$. Elevated levels of CXCR5 + CD8 + T cells in the Klebsiella pneumoniae infected-group were markedly higher than these in the others group. Given the severity of Klebsiella pneumoniae infections and dependence of generation of CXCR $5+\mathrm{CD} 8+\mathrm{T}$ cell on antigen persistence, these cells are associated with developing immune response against highly pathogenic Klebsiella pneumoniae.

It was reported that circulating HIV-specific CXCR5 + CD8+ T-cells had a higher production of IL-21 than CXCR5- cells [5]. And follicular cytotoxic CD8+ T cells express granzyme $\mathrm{A}$ and $\mathrm{B}$ and perforin at higher levels than their CXCR5- counterpart [16]. We also characterized the function state of circulating CXCR5-expressing T-cells by the expression of PD-1. In our study, we identified circulating CXCR5 + CD8+ T-cells and CXCR5-CD8+ T-cells, which exhibited comparable level of PD-1. It has been indicated that virus-specific CD8+ T cells present in GCs of humans and macaques may not be enough to clear the increasing population of infected TFH cells. Taken together, the increase of CXCR5 + CD8 + T cell may be functionally impaired or exhausted.

Whether circulating CXCR5+ cells are the resident counterpart of $\mathrm{CD} 8+\mathrm{T}$ cells has been controversial. Here, CXCR5 + CD8 + T cells did not be defined as TCM cells by virtue of negative CD103 expression $[17,18]$. Then, these cells might provide new correlates of protection, disease progression, or treatment response, pointing toward potential therapeutic strategies.

There are still limitations about this research. The detailed mechanism of increased CXCR5 + CD8 $+\mathrm{T}$ cells need to be further researched. The function of these cells in bacterial infection should also be studied thoroughly in future.

\section{Conclusion}

Taken together, the current study explored the diagnostic value of circulating CXCR5 + CD8+ T cells in bacterial respiratory infections. Overall, our studies on circulating CXCR5 + CD8 + T cells have shed light on the its important role in the pathogenesis process of uncontrolled respiratory bacterial infectious diseases. It was indicated that candidate bacterial vaccines should attempt to preferentially elicit these cells.

\section{Abbreviations}

BALF: Bronchoalveolar lavage fluid; CAP: Community acquired pneumonia; CRP: C-reactive protein; CXCR5: C-X-C chemokine receptor type 5;
FACS: Fluorescence activated cell sorter; GC: Germinal center; HAP: Hospital acquired pneumonia; K.p: Klebsiella pneumonia; LCMV: Lymphocytic choriomeningitis virus; LN: Lymph node; PCT: Procalcitonin; ROC: Receiver operating characteristic curve; TFC: T follicular helper cells

\section{Acknowledgements}

We thank Prof. Binfeng Lu (University of Pittsburgh, USA) for reviewing the manuscript.

\section{Funding}

This work was supported by the Project of National Natural Science Foundation of China (81672280), Project of Suzhou City (SYS2018042) and Medical Youth of Jiangsu Province (QNRC2016748). The funders had no role in the study design, data collection and analysis, decision to publish, or preparation of the manuscript.

\section{Availability of data and materials}

All data generated or analyzed during this study are included in this published article.

\section{Authors' contributions}

CC participated in the conception, the design and coordination of the study, collected data, and drafted the manuscript. SY and QQX conceived of the study, and participated in its design and coordination and helped to draft the manuscript. JMN participated in collected data. All authors read and approved the final manuscript.

\section{Ethics approval and consent to participate}

The study was approved by the Ethics Committee of our Institute of the First Affiliated Hospital of Soochow University (2016-124-1).

\section{Consent for publication}

Written informed consent was obtained from the patient or legal representative.

\section{Competing interests}

The authors declare that they have no competing interests.

\section{Publisher's Note}

Springer Nature remains neutral with regard to jurisdictional claims in published maps and institutional affiliations.

\section{Author details}

${ }^{1}$ Clinical Immunology Laboratory, the First Affiliated Hospital of Soochow University, 188 Shizi Street, Suzhou 215006, China. ${ }^{2}$ Jiangsu Key Laboratory of Clinical Immunology, Soochow University, 708 Renmin Road, Suzhou 215006, China. ${ }^{3}$ Respiratory Department, the First Affiliated Hospital of Soochow University, 188 Shizi Street, Suzhou 215006, China.

Received: 17 September 2018 Accepted: 20 February 2019 Published online: 12 March 2019

\section{References}

1. Haynes NM, Allen CD, Lesley R, Ansel KM, Killeen N, Cyster JG. Role of CXCR5 and CCR7 in follicular Th cell positioning and appearance of a programmed cell death gene-1 high germinal center associated subpopulation. J Immunol. 2007;179(8):5099-108.

2. He R, Hou S, Liu C, Zhang A, Bai Q, Han M, Yang Y, Wei G, Shen T, Yang X, Xu L, Chen X, Hao Y, Wang P. Follicular CXCR5- expressing CD8(+) T cells curtail chronic viral infection. Nature. 2016;537(7620):412-28.

3. Im SJ, Hashimoto M, Gerner MY, Lee J, Kissick HT, Burger MC, Shan Q, Hale J, Lee J, Nasti TH, Sharpe AH, Freeman GJ, Germain RN, Nakaya HI, Xue HH, Ahmed R. Defining CD8+ T cells that provide the proliferative burst after PD-1 therapy. Nature. 2016;537(7620):417-21.

4. Bai M, Zheng Y, Liu H, Su B, Zhan Y, He H. CXCR5+ CD8+ T cells potently infiltrate pancreatic tumors and present high functionality. Exp Cell Res. 2017:361(1):39-45.

5. Federico PC, Natalia AT, Maria TR. Circulating CXCR5-expressing CD8+ T-cells are major producers of IL-21 and associate with limited HIV replication. J Acquir Immune Defic Syndr. 2018;78(4):473-82. 
6. Christ-Crain M, Müller B. Biomarkers in respiratory tract infec-tions: diagnostic guides to antibiotic prescription, prognosticmarkers and mediators. Eur Respir J. 2007;30(3):556-73.

7. Wacker C, Prkno A, Brunkhorst FM, Schlattmann P. Procalcitoninas a diagnostic marker for sepsis: a systematic review and meta-analysis. Lancet Infect Dis. 2013;13(5):426-35.

8. Lim HF, Phua J, Mukhopadhyay A, Ngerng WJ, Chew MY, Sim TB, Kuan WS, Mahadevan M, Lim TK. IDSA/ATS minor criteria aid pre-intensive care unit resuscitation in severe community-acquired pneumonia. Eur Respir J. 2014; 43(3):852-62.

9. Martin-Loeches I, Rodriguez AH, Torres A. New guidelines for hospitalacquired pneumonia/ventilator-associated pneumonia: USA vs. Europe. Curr Opin Crit Care. 2018;24(5):347-52.

10. Mylvaganam GH, Rios D, Abdelaal HM, lyer S, Tharp G, Mavigner M, Hicks S, Chahroudi A, Ahmed R, Bosinger SE. Dynamics of SIV-specific CXCR5 CD8 T cells during chronic SIV infection. Proc Natl Acad Sci U S A. 2017;114(8):1976-81.

11. Li S, Folkvord JM, Rakasz EG, Abdelaal HM, Wagstaff RK, Kovacs KJ, Kim HO, Sawahata R, MaWhinney S, Masopust D. Simian immunodeficiency virusproducing cells in follicles are partially suppressed by CD8+ cells in vivo. J Virol. 2016;90(24):11168-80.

12. Simon L, Gauvin F, Amre DK, Saint-Louis P, Lacroix J. Serum procalcitonin and C-reactive protein levels as markers of bacterial infection: a systematic review and meta-analysis. Clin Infect Dis. 2004;39(2):206-17.

13. Nakamura Y, Murai A, Mizunuma M, Ohta D, Kawano Y, Matsumoto N, Nishida T, Ishikura H. Potential use of procalcitonin as biomarker for bacterial sepsis in patients with or without acute kidney injury. J Infect Chemother. 2015;21(4):257-63.

14. Karaiskos I, Giamarellou H. Multidrug-resistant and extensively drug-resistant gram-negative pathogens: current and emerging therapeutic approaches. Expert Opin Pharmacother. 2014;15(10):1351-70

15. Tzouvelekis LS, Markogiannakis A, Piperaki E, Souli M, Daikos GL. Treating infections caused by carbapenemase-producing Enterobacteriaceae. Clin Microbiol Infect. 2014;20(9):862-72.

16. Leong YA, Chen Y, Ong HS, Wu D, Man K, Deleage C, Minnich M, Meckiff BJ, Wei Y, Hou Z, Zotos D, Fenix KA, Atnerkar A, Preston S, Chipman JG, Beilman GJ, Allison CC, Sun L, Wang P, Xu J, Toe JG, Lu HK, Tao Y, Palendira U, Dent AL, Landay AL, Pellegrini M, Comerford I, McColl SR, Schacker TW, Long HM, Estes JD, Busslinger M, Belz GT, Lewin SR, Kallies A, Yu D. CXCR5(+ ) fol-licular cytotoxic T cells control viral infection in B cell follicles. Nat Immunol. 2016;17(10):1187-96.

17. Gebhardt T, Wakim LM, Eidsmo L, Reading PC, Heath WR, Carbone FR Memory T cells in nonlymphoid tissue that provide enhanced local immunity during infection with herpes simplex virus. Nat Immunol. 2009; 10(5):524-30.

18. Sathaliyawala T, Kubota M, Yudanin N, Turner D, Camp P, Thome JJ, Bickham KL, Lerner H, Goldstein M, Sykes M, Kato T, Farber DL. Distribution and compartmentalization of human circulating and tissue-resident memory T cell subsets. Immunity. 2013;38(1):187-97.

Ready to submit your research? Choose BMC and benefit from:

- fast, convenient online submission

- thorough peer review by experienced researchers in your field

- rapid publication on acceptance

- support for research data, including large and complex data types

- gold Open Access which fosters wider collaboration and increased citations

- maximum visibility for your research: over $100 \mathrm{M}$ website views per year

At $\mathrm{BMC}$, research is always in progress.

Learn more biomedcentral.com/submissions 